\title{
Research Paper: The Relationship Between Antioxidants and Inflammation in Children With Attention Deficit Hyperactivity Disorder
}

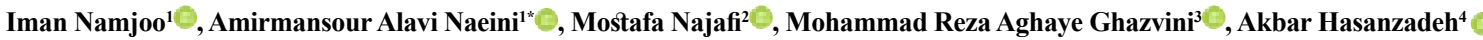 \\ 1. Department of Community Nutrition, School of Nutrition and Food Sciences, Isfahan University of Medical Sciences, Isfahan, Iran. \\ 2. Department of Psychiatry, Behavioral Sciences Research Center, School of Medicine, Isfahan University of Medical Sciences, Isfahan, Iran. \\ 3. Isfahan Center of Health Research, National Institute of Health Research, Isfahan, Iran. \\ 4. Department of Biostatistics and Epidemiology, School of Health, Isfahan University of Medical Sciences, Isfahan, Iran.
}

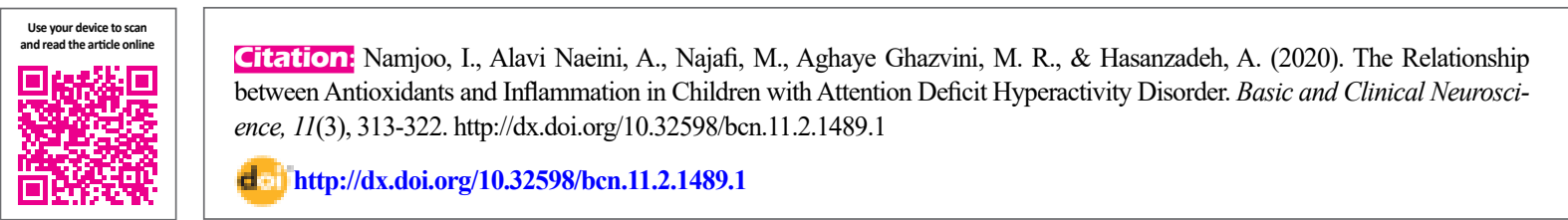

Article info:

Received: 14 Aug 2018

First Revision: 02 Sep 2018

Accepted: 09 Feb 2020

Available Online: 01 May 2020

Keywords:

Antioxidants, Inflammation, C-Reactive protein, Attention Deficit Disorder with Hyperactivity, Child

\section{AB S T RA C T}

Introduction: Recent studies have identified Attention Deficit Hyperactivity Disorder (ADHD) as an inflammatory condition associated with immunological and oxidative responses. Therefore, it is necessary to examine these processes in these patients. The present study aimed at investigating the relationship between the dietary intake of antioxidants, Superoxide Dismutase (SOD) activity, and the serum levels of inflammatory factors in ADHD students.

Methods: This retrospective case-control study was conducted on 64 ADHD children aged 6 - 13 years. The demographic questionnaire, Food Frequency Questionnaire, and Baecke Physical Activity Questionnaire were used for data collection. SOD activity and the serum level of inflammatory factors (homocysteine, interleukin-6, and C-reactive Protein (CRP)) were measured in all patients. According to the CRP values, 32 patients were included in the case group $(\mathrm{CRP} \geq 1 \mathrm{mg} / \mathrm{L})$ and 32 patients in the control group $(0 \leq \mathrm{CRP}<1 \mathrm{mg} / \mathrm{L})$.

Results: There was no significant difference between the two groups in age, sex, weight, height, and body mass index. In the case group, the mean SOD activity $(\mathrm{P}=0.034)$, the physical activity $(\mathrm{P}=0.04)$, zinc intake $(\mathrm{P}=0.02)$, and homocysteine levels were higher than the control group $(\mathrm{P}=0.001)$. Of all studied variables, the best predictors were homocysteine $(\mathrm{OR}$ : $1.34,95 \% \mathrm{CI}: 1.082-1.670, \mathrm{P}=0.029)$ and physical activity (OR: $0.85,95 \% \mathrm{CI}: 0.761-$ $0.952, \mathrm{P}=0.022$ ) respectively, whereas other variables were not significant predictors.

Conclusion: The present study showed that the level of inflammatory factors in the case group was significantly higher than the control group. Homocysteine and physical activity can predict the inflammation status induced by CRP.

\section{* Corresponding Author:}

Amirmansour Alavi Naeini, PhD.

Address: Department of Community Nutrition, School of Nutrition and Food Sciences, Isfahan University of Medical Sciences, Isfahan, Iran.

Tel: +98 (313) 7923154

E-mail:am.alavi@nutrmui.ac.ir 


\section{Highlights}

- The activity of superoxide dismutase, an antioxidant enzyme, decreases with elevated C-reactive Protein (CRP).

- The levels of CRP are associated with homocysteine and interleukin-6 levels.

- Homocysteine and physical activity can predict the inflammation status induced by CRP.

\section{Plain Language Summary}

The most common neurodevelopmental disorder in children is Attention Deficit Hyperactivity Disorder (ADHD) that is associated with academic, social, and occupational problems. Therefore, the high costs and side effects of this disorder have directed researchers towards exploring strategies for preventing, controlling, and treating it. Recent studies have identified $\mathrm{ADHD}$ as an inflammatory condition with oxidative responses. Therefore, it is necessary to examine these processes in these patients. The present study aimed at investigating the relationship between the dietary intake of Antioxidants, Superoxide Dismutase (SOD) antioxidant enzyme activity, and the serum levels of inflammatory factors in students with ADHD. Accordingly, 64 ADHD children aged 6 - 13 years old were divided into two groups based on C-reactive protein (CRP) serum levels: 32 patients in the case group ( $\mathrm{CRP} \geq 1 \mathrm{mg} / \mathrm{L})$ and 32 patients in the control group $(0 \leq \mathrm{CRP}<1 \mathrm{mg} / \mathrm{L})$. CRP is one of the most important biomarkers of inflammatory disease. SOD activity and the serum level of inflammatory factors (homocysteine, interleukin-6, and CRP) were measured in all patients. The findings indicated that SOD activity decreased with elevated CRP. The levels of CRP were associated with homocysteine and interleukin-6 levels. Homocysteine and physical activity can predict the inflammation status associated with CRP.

\section{Introduction}

he most common neurodevelopmental ก disorder in children is Attention Deficit Hyperactivity Disorder (ADHD), which is associated with inattention, hyperactivity, impulsivity, and distraction, and often continues until adolescence and adulthood (Anney et al., 2008). These patients usually face academic, social, and occupational problems; therefore, the high costs and side effects of this disorder have directed researchers towards exploring strategies for preventing, controlling, and treating ADHD (Anney et al., 2008; Stoltz, 2004). Although its etiology remains unclear, genetic and environmental factors and their interactions have been investigated in various studies (Crosbie \& Schachar, 2001).

ADHD is an inflammatory condition with immunological responses and oxidative stress. The ability to pass inflammatory mediators from the blood-brain barrier and its effect on the metabolism of some amino acids (such as tryptophan), dopaminergic and noradrenergic systems, and on the function of neurons and synapses, may indicate the role of inflammatory mediators in ADHD pathology (Oades, Dauvermann, Schimmelmann, Schwarz, \& Myint, 2010). Stressful life events experienced during and after pregnancy and subsequent im- munological responses may interfere with the balance of pro-inflammatory/anti-inflammatory mediators and ultimately lead to further increase in inflammatory factors, such as Tumor Necrosis Factor (TNF) and pro-inflammatory interleukins. These inflammatory mediators can lead to neuronal degeneration and behavioral problems (Ma, Chen, Chen, Liu, \& Wang, 2011; Martino, Rocchi, Escelsior, \& Fornaro, 2012). Recently, the relationship between inflammatory markers and the consequences of neurodevelopmental growth among children has been studied. One cohort study introduced inflammation as an independent risk factor, which may disrupt the neuronal development of children, and high levels of C-reactive protein (CRP), as one of the most important inflammatory factors (Jiang et al., 2017). Although recent studies have introduced CRP as a risk factor for cardiovascular diseases, increased levels of CRP have been seen in neuropsychiatric disorders, such as chronic depression (Miller, Freedland, Carney, Stetler, \& Banks, 2003; Ridker, Hennekens, Buring, \& Rifai, 2000). Studies on the role of inflammatory factors in ADHD are contradictory and limited. According to the epidemiological studies, there is a significant and direct correlation between homocysteine levels and cognitive disorders (bipolar disorder, autism, and Alzheimer Disease (AD)); however, one study has shown a reduction in homocysteine levels in ADHD (Karababa et al., 2017; Refsum et al., 2004). 
In addition to inflammatory and immunologic factors, oxidative metabolism is considered as one of the most important mechanisms in the development of ADHD. Some cross-sectional studies have shown that oxidative balance is impaired in patients with ADHD (Selek, Bulut, Ocak, Kalenderoglu, \& Savas, 2012), whereas in a study on children with ADHD, no relationship between oxidative stress and this disorder was observed (Oztop, Altun, Baskol, \& Ozsoy, 2012). According to the results of a meta-analysis, the relationship between antioxidant status and ADHD was not significant; however, responses to oxidative stress were inadequate (Joseph, Zhang-James, Perl, \& Faraone, 2015).

The relationship between nutrients (macronutrients and micronutrients) and the immune system has always been relevant; some nutrients are known as immune system regulators and others as pro-inflammatory or antiinflammatory agents (Thaler \& Schwartz, 2010). Some studies have highlighted the high dietary fat intake and obesity as inflammatory factors in the nervous system (Yi, Tschop, Woods, \& Hofmann, 2012). However, other studies have shown that the intake of sufficient amounts of omega-3 fatty acids can play a significant role in preventing neuroinflammatory diseases. Fat-soluble vitamins, especially vitamin A, vitamin $\mathrm{D}$, and vitamin $\mathrm{E}$, play a potential role in regulating the production of immune cells and reducing inflammation (Cha et al., 2010). Few studies have been carried out on the role of food antioxidants in ADHD. The plasma levels of micronutrients, such as zinc and copper, which play an important role in the antioxidant defense mechanism, are lower in ADHD children than in healthy people (Yorbik, Olgun, Kırmızıgül, \& Akman, 2004). In addition, Superoxide Dismutase (SOD) activity, as the first and most important antioxidant defense enzyme, is lower in these patients (Selek, Savas, Gergerlioglu, Bulut, \& Yilmaz, 2008). On the other hand, vitamin $\mathrm{E}$ with an antioxidant effect by reducing lipid peroxidation is effective in the treatment of ADHD (Tsaluchidu, Cocchi, Tonello, \& Puri, 2008).

Due to the limited number of studies and the importance of treating and controlling ADHD, this study was aimed at determining the relationship between dietary intake of antioxidants and physical activity, SOD enzyme activity, and serum levels of inflammatory factors in 6-13-year-old students with ADHD.

\section{Methods}

\subsection{Study design and participants}

This retrospective case-control study was conducted on 98 ADHD children (diagnosed by a child and adolescent psychiatrist) aged between 6 and 13 years who had been referred to the psychiatric center of Isfahan University of Medical Sciences (Isfahan Behavioral Sciences Research Center at Noor Hospital) in Isfahan, Iran from November to March 2016. The inclusion criteria included the age between 6 to 13 years, cases with ADHD diagnosed by a psychiatrist, taking a certain dose of Ritalin, a Body Mass Index (BMI) within the normal range, no other chronic diseases, no use of nutritional supplements or medicines other than Ritalin, and following no particular diet. Informed consent to include the children in the study was completed by their parents.

\subsection{Data collection}

A general questionnaire assessing personal information, medical history, and medications used was completed. The body weight and height of the children were measured without shoes and with light indoor clothing. A Food Frequency Questionnaire (FFQ), which is a 168-item scale and its validity and reliability, has been confirmed in previous studies (Mirmiran, Esfahani, Mehrabi, Hedayati, \& Azizi, 2010), was used to determine nutrient intake. The dietary intakes of vitamin $\mathrm{E}$, vitamin $\mathrm{C}$, alpha-tocopherol, beta-carotene, selenium, and zinc were obtained using the FFQ for the last year. Dietary data were analyzed using the Nutritionist-4 software (First Databank Inc., Hearst Corp., San Bruno, CA, USA). This software presented the nutrient intakes. The physical activity of the subjects was measured using the Baecke questionnaire (16 items) (Baecke, Burema, \& Frijters, 1982; Maddah, Eshraghian, Djazayery, \& Mirdamadi, 2003).

Blood sampling was performed by a qualified expert and SOD activity and the serum levels of inflammatory factors (CRP, interleukin-6 (IL-6), and homocysteine) were measured. The serum levels of CRP were classified as low if the CRP was $<1$ and $=0 \mathrm{mg} / \mathrm{L}$ or as high if the CRP was $\geq 1 \mathrm{mg} / \mathrm{L}$. Based on the classification of the American Heart Association, an individual with a CRP greater than $1 \mathrm{mg} / \mathrm{L}$ compared to a CRP of less than $1 \mathrm{mg} / \mathrm{L}$ is exposed to inflammation and a greater risk of chronic diseases, such as coronary artery diseases (Pearson et al., 2003). Based on the obtained results, 32 patients with $\mathrm{CRP} \geq 1 \mathrm{mg} / \mathrm{L}$ were chosen for the case group and 32 patients with $0 \leq \mathrm{CRP}<1 \mathrm{mg} / \mathrm{L}$ for the control group who were matched by gender and age. Other subjects were excluded from the study because they did not belong to either of the two groups.

\subsection{Laboratory procedures}

SOD activity was measured by spectrophotometry using the ZellBio GmbH kit (Germany) with Intra/Inter- 
assay Coefficients of Variations (CV); 5.8/7.2\%. The serum levels of IL-6 and homocysteine were measured by the Enzyme-linked Immunosorbent Assay (ELISA) method and measured using the kits from the DIACLON Company, France (Intra/Inter-assay CV; 4.1/6.2\%) and Axis-Shield Diagnostic Ltd, UK (Inter-assay CV; 7.2\%), respectively. CRP was measured by the ELISA method using Pars Azmoon kits (Tehran, Iran) with an inter-assay CV of $1.7 \%$. All biochemical parameters were evaluated in the Hasht-Behesht laboratory, Isfahan, under the direct supervision of the relevant specialist.

\subsection{Statistical analysis}

The normality of data was checked by the ShapiroWilk test. The Chi-squared test and independent samples t-tests were used to analyze qualitative and quantitative data, respectively. The logistic regression model was used to predict the patients' groups $(\mathrm{CRP} \geq 1 \mathrm{mg} / \mathrm{L}$ or $0 \leq \mathrm{CRP}<1 \mathrm{mg} / \mathrm{L})$. The statistical analysis was done using SPSS 22 software (IBM Corporation, Armonk, NY, USA) and the P-value $<0.05$ was statistically significant.

\section{Results}

Based on Table 1, there was no significant difference in age, sex, weight, height, and BMI in the two groups $(\mathrm{CRP} \geq 1 \mathrm{mg} / \mathrm{L}$ or $0 \leq \mathrm{CRP}<1 \mathrm{mg} / \mathrm{L})$.

The Mean \pm SD of the physical activity score in the case group was significantly lower than that of the control group. The Mean \pm SD of the CRP, IL-6, homocysteine, SOD, and dietary intake of antioxidants are presented in Table 2. The Mean \pm SD of IL-6 in the case group was significantly more than the control group $(\mathrm{P}=0.055)$. ADHD patients had significantly higher homocysteine levels in the case group $(\mathrm{P}=0.001)$. The mean $\pm \mathrm{SD}$ of SOD activity $(\mathrm{P}=0.034)$ and zinc intake $(\mathrm{P}=0.020)$ in the case group was significantly lower in comparison with the control group. There was no significant difference in the dietary intake of vitamin $\mathrm{E}(\mathrm{P}=0.549)$, vitamin $\mathrm{C}$ $(\mathrm{P}=0.375)$, beta-carotene $(\mathrm{P}=0.465)$, alpha-tocopherol $(\mathrm{P}=0.458)$, and selenium $(\mathrm{P}=0.589)$.

The variables with a significant relationship with CRP in the independent t-test were entered into a logistic regression model (Table 2) to predict the patients' groups $(\mathrm{CRP} \geq 1 \mathrm{mg} / \mathrm{L}$ or $0 \leq \mathrm{CRP}<1 \mathrm{mg} / \mathrm{L})$. This model showed that these variables can accurately predict $82.1 \%$ of patients in which group they are. The sensitivity (the really high levels of CRP) and specificity (the really low levels ofCRP) of this model were $81.8 \%$ and $82.4 \%$, respectively. Among the variables, the best predictors were homo- cysteine (OR: 1.34, 95\% CI: 1.082-1.670, $\mathrm{P}=0.029$ ) and physical activity (OR: $0.85,95 \% \mathrm{CI}: 0.761-$ $0.952, \mathrm{P}=0.022$ ), respectively, whereas other variables were not significant predictors.

\section{Discussion}

The present study aimed at determining the relationship between antioxidant food intake and SOD activity and the serum levels of inflammatory mediators in children with ADHD. According to the result of the study, the levels of IL-6 and homocysteine, as inflammatory factors, were significantly higher in the case group compared with the control group. Among the variables, the best predictors were homocysteine and physical activity, respectively, whereas other variables were not significant predictors.

Special attention has recently given to the relationship between inflammatory factors and neurodevelopmental growth (Leviton et al., 2016). A cohort study in 2017 by Jiang et al. showed that high levels of CRP and IL-6 led to a defect in children's neurodevelopmental growth. CRP, as a systemic inflammatory biomarker, has grabbed attention in neuropsychiatric disorders, such as chronic depression and cardiovascular diseases (Jiang et al., 2017; Penninx et al., 2003).

CRP may play an important role in ADHD patients. The results of a systematic review (2014) presented primary evidence regarding the role of inflammation in psychiatric disorders among children and teenagers (Mitchell \& Goldstein, 2014). Nonetheless, studies regarding the relationship between inflammatory factors and ADHD are limited. High levels of inflammatory cytokines have been observed in the brain of many patients suffering from $\mathrm{AD}$, depression, and bipolar disorder. However, two studies have been conducted on ADHD, one of which has shown an increase in cytokines in the cerebrospinal fluid, whereas the other has shown an increase in cytokines in plasma (Oades, Myint, Dauvermann, Schimmelmann, \& Schwarz, 2010). IL-1 and IL-6 change the metabolism of central neurotransmitters, such as norepinephrine and dopamine (Anisman, Kokkinidis, \& Merali, 1996; Dunn, Wang, \& Ando, 1999). IL-6 is produced by stimulating TNF- $\alpha$ and enhances the synthesis of CRP in the liver (Laimer et al., 2002). Considering these mechanisms, inflammation might play a role in ADHD pathogeneses.

Homocysteine is considered as a potential cause of physical and mental diseases, such as strokes, depression, cognitive disorders, bipolar disorder, and AD (Mc- 
Table 1. General characteristics and other variables of the study participants $(n=32)$ *

\begin{tabular}{|c|c|c|c|}
\hline \multirow{2}{*}{ Variables } & \multicolumn{2}{|c|}{ Mean $\pm S D / N O .(\%)$} & \multirow{2}{*}{$\mathrm{P} * *$} \\
\hline & $\begin{array}{l}\text { ADHD with CRP } \geq 1 \\
\text { Case Group }\end{array}$ & $\begin{array}{c}\text { ADHD with } 0 \leq C R P<1 \\
\text { Control Group }\end{array}$ & \\
\hline Age (y) & $9.15 \pm 1.563$ & $9.06 \pm 1.529$ & 0.806 \\
\hline \multirow[b]{2}{*}{ Gender } & $26(40.6)$ & $26(40.6)$ & \\
\hline & & & 0.964 \\
\hline Female & $6(9.4)$ & $6(9.4)$ & \\
\hline Weight (kg) & $31.08 \pm 9.071$ & $31.16 \pm 9.546$ & 0.971 \\
\hline Height $(\mathrm{cm})$ & $134.31 \pm 10.953$ & $135.35 \pm 12.796$ & 0.716 \\
\hline $\mathrm{BMI}\left(\mathrm{kg} / \mathrm{m}^{2}\right)$ & $16.95 \pm 2.892$ & $16.78 \pm 3.434$ & 0.820 \\
\hline Physical activity (score) & $18.92 \pm 3.996$ & $20.30 \pm 4.709$ & 0.044 \\
\hline $\mathrm{CRP}(\mathrm{mg} / \mathrm{L})$ & $1.44 \pm 0.441$ & $0.64 \pm 0.254$ & $<0.001$ \\
\hline Interleukin-6 (pg/L) & $9.25 \pm 1.178$ & $8.17 \pm 2.583$ & 0.055 \\
\hline Homocysteine ( $\mu \mathrm{mol} / \mathrm{L})$ & $6.70 \pm 3.292$ & $3.52 \pm 4.200$ & 0.001 \\
\hline SOD activity (U/ml) & $4.55 \pm 0.978$ & $5.66 \pm 2.614$ & 0.034 \\
\hline Vitamin E intake (mg/day) & $16.60 \pm 13.098$ & $18.51 \pm 13.286$ & 0.549 \\
\hline Vitamin C intake (mg/day) & $65.85 \pm 35.842$ & $76.23 \pm 61.644$ & 0.375 \\
\hline Beta-carotene intake ( $\mu \mathrm{g} /$ day) & $406.55 \pm 415.63$ & $508.65 \pm 745.84$ & 0.465 \\
\hline Alpha-tocopherol intake (mg/day) & $12.42 \pm 8.047$ & $13.93 \pm 8.961$ & 0.458 \\
\hline Zinc intake (mg/day) & $7.17 \pm 1.706$ & $8.64 \pm 3.059$ & 0.020 \\
\hline Selenium intake ( $\mathrm{mg} /$ day) & $0.061 \pm 0.045$ & $0.066 \pm 0.029$ & 0.589 \\
\hline
\end{tabular}

* All values are presented as Mean \pm SD or percentage (\%);

** P-values obtained by the Independent sample t-test.

Cully, 2009; Stanger et al., 2009). Homocysteine causes functional and cognitive disorders in youth with schizophrenia and bipolar disorder (Dittmann et al., 2008). Although the level of homocysteine increases in cognitive disorders, such as AD, bipolar disorder and autism, in a study conducted by Karababa et al. (2017) to compare the level of homocysteine and antioxidant indices in two groups of healthy and ADHD adults, it was shown that the level of homocysteine in ADHD patients was lower than that in the control group. Also, no significant difference was observed in the level of antioxidant indices in the two groups (Karababa et al., 2017). However, SOD activity in the case group was significantly higher than that of the control group in the present study.

Numerous studies have shown that free radicals play a crucial role in the pathology of depression, bipolar disorder, and other psychological disorders (Papas, 1996; Stadtman, 2006). About $75 \%$ of hyperactive adults suffer from other psychological disorders, such as stress, depression, and bipolar disorder (Tarazi, Zhang, \& Baldessarini, 2002). Based on such evidence, an increase in oxidative stress might be observed in ADHD patients. An increase in oxidative stress leads to increased dopamine release by increasing the penetrability of the membrane to calcium. Since dopamine is 
Table 2. The results of logistic regression analysis of variables to predict the patients' groups

\begin{tabular}{|c|c|c|c|c|c|c|c|}
\hline \multirow{2}{*}{ Variables } & \multirow{2}{*}{ Coefficient (ß) } & \multirow{2}{*}{$\begin{array}{c}\text { Standard Error } \\
\text { SE }\end{array}$} & \multirow{2}{*}{ Wald } & \multirow{2}{*}{$\mathrm{P}^{*}$} & \multirow{2}{*}{$\begin{array}{l}\text { Odds Ratio } \\
\text { OR }\end{array}$} & \multicolumn{2}{|c|}{$95 \% \mathrm{Cl}$ for OR } \\
\hline & & & & & & Lower & Upper \\
\hline Interleukin-6 & 0.260 & 0.271 & 0.921 & 0.337 & 1.296 & 0.763 & 2.203 \\
\hline Homocysteine & 0.296 & 0.136 & 4.477 & 0.029 & 1.344 & 1.082 & 1.670 \\
\hline SOD activity & -0.051 & 0.114 & 0.205 & 0.650 & 0.950 & 0.792 & 1.139 \\
\hline Zinc intake & -0.733 & 0.413 & 3.153 & 0.076 & 0.480 & 0.214 & 1.079 \\
\hline Physical activity & -0.161 & 0.070 & 5.250 & 0.022 & 0.851 & 0.761 & 0.952 \\
\hline
\end{tabular}

* P-values obtained by the Pearson correlation.

NEUR $\$ S C I E N C E$

an important neurotransmitter in ADHD, an increase in dopamine release due to an increase in oxidative stress can be influential in the pathogenesis of this disorder (Selek et al., 2008). Kul, Unal, Kandemir, Sarkarati, Kilinc, \& Kandemir (2015) showed that oxidative stress is significantly higher in ADHD children. Other studies are also consistent with this finding (Guney et al., 2015; Sezen et al., 2016). Selek et al. found that SOD activities in adults with ADHD were lower in comparison with the control group. Besides, high levels of nitric oxide antioxidant and low SOD activities indicate the lack of oxidative balance in these patients (Selek et al., 2008). An increase in these oxidant parameters represents the role of inflammation in ADHD because the overproduction of oxidants can lead to the body's inflammatory responses (Vida, Gonzalez, \& De la Fuente, 2014).

Naghashpour et al. reported no significant relationship between the food intake of B vitamins (folate, riboflavin, thiamine, and cobalamin), vitamins $\mathrm{D}$ and $\mathrm{C}$, magnesium, zinc, and total daily calories, and hs-CRP serum levels in healthy and depressed groups (Naghashpour, Amani, Nutr, Nematpour, \& Haghighizadeh, 2011). These results are consistent with the findings of previous studies (Bertran et al., 2005; Ghayour-Mobarhan, Yaghootkar, Lanham-New, Lamb, \& Ferns, 2007). However, in the present study, there was an inverse and insignificant correlation between the food intake of vitamins $\mathrm{E}$ and $\mathrm{C}$, beta-carotene, alpha-tocopherol, zinc, and selenium, and CRP levels (Naghashpour et al., 2011). Bertran et al. showed that reducing the amount of food (e.g. reducing the intake of carbohydrate, protein, lipid, thiamine, alpha-tocopherol, and folate quantities) is related to higher concentrations of CRP plasma (Bertran et al., 2005). Nonetheless, most of these relationships were not observed in the multi-variant analysis. Furthermore, Naghashpour et al. showed a significant difference among depressed individuals in the intake of vitamin $\mathrm{E}$ in various quartiles of hs-CRP serum levels. Patients in the second quartile had significantly less vitamin $\mathrm{E}$ intake than those in the fourth quartile (Naghashpour et al., 2011). Another study showed an inverse relationship between vitamin $\mathrm{E}$ and levels of serum CRP (Seddon, Gensler, Klein, \& Milton, 2006). However, Fredrikson et al. found no significant relationship between levels of serum CRP and vitamin E and beta-carotene intake (Fredrikson, Hedblad, Nilsson, Alm, Berglund, \& Nilsson, 2004).

Zinc plays a crucial role in the cell growth and cognitive evolution of children and its levels are high in brain areas responsible for structural and operational functions (Benton, 2010; Black, 1998). Zinc deficiency in children is associated with the reduced cognitive and motor function (Bryan et al., 2004), as well as a higher prevalence of depression and ADHD (DiGirolamo \& Ramirez-Zea, 2009). Zinc is necessary for neurogenesis, neural migration, and synaptogenesis and its deficiency can stop neural transference (Bhatnagar \& Taneja, 2001). Yorbik et al. announced that plasma levels of zinc, which play a role in the antioxidant defense mechanism, were lower in ADHD children compared with the control group (Yorbik et al., 2004). Moreover, cross-sectional studies have indicated the shortage of zinc in children suffering from ADHD. Additionally, serum zinc levels are closely related to inattention scores (Eugene Arnold et al., 2005). Nonetheless, it is not clear whether the differences in diet were related to the period before the emergence of behavioral problems or the behavioral changes had influenced the food intake.

Exercise reduces inflammation, particularly the level of CRP in the blood, as a marker of inflammation (Balagopal et al., 2005; Tsang, Kohn, Chow, \& Singh, 2009). An inverse relationship has shown between physical activity 
and levels of inflammatory markers in older adults (Ertek \& Cicero, 2012; Hamer et al., 2012) and in children and young adults (Isasi et al., 2003), which is in agreement with our findings. However, no association has reported in other studies conducted on children (Carson et al., 2013). On the other hand, a positive association has been found between increased physical activity and a decrease in ADHD symptoms, particularly the cognitive and behavioral outcomes (Song, Lauseng, Lee, Nordstrom, \& Katch, 2016). Based on our findings, physical activity predicts serum levels of CRP and inflammation status in these patients. Because the most obvious sign of ADHD is hyperactivity and also due to the role of physical activity in reducing inflammation, more studies are needed to determine the effect of increased physical activity and regular exercise on symptoms and inflammation status in these patients.

The present case-control study was a first attempt to investigate antioxidant food intake, SOD activities, and serum levels of inflammatory mediators in children suffering from $\mathrm{ADHD}$ assigned to the two groups of $\mathrm{CRP} \geq 1$ $\mathrm{mg} / \mathrm{L}$ and $0 \leq \mathrm{CRP}<1 \mathrm{mg} / \mathrm{L}$. One of the most important strengths of the present study was its subject, that is, studying CRP as one of the most important inflammatory markers of chronic diseases and investigating the relationship between taking antioxidants and SOD activity. The limitation of this study was its small sample size and no assessment of indices, such as mental functions related to disease severity.

Finally, our results showed that the level of inflammatory factors in the case group was significantly higher than the control group. Homocysteine and physical activity can predict the inflammation status induced by CRP. Further studies with larger sample sizes should be carried out to confirm these results.

\section{Ethical Considerations}

\section{Compliance with ethical guidelines}

The Ethics Committee of Isfahan University of Medical Sciences approved the present study (Ethics Code: IR.MUI.REC.1395.3.370). Written informed consent was gained from the parents of the participants before taking part in the study. All participants were allowed to withdraw from the study. All data obtained from individuals are considered confidential and are used only for research purposes, and the patient's identity will be confidential within the framework of the rules.

\section{Funding}

This study was extracted from the MSc. thesis approved and granted by the School of Nutrition \& Food Sciences, Isfahan University of Medical Sciences (No.: 395370).

\section{Authors' contributions}

Conceptualization: Amirmansour Alavi Naeini, Iman Namjoo, Mostafa Najafi; Methodology: Amirmansour Alavi Naeini, Iman Namjoo, Akbar Hasanzadeh; Investigation: Amirmansour Alavi Naeini, Iman Namjoo; Writing-original draft: Iman Namjoo, Amirmansour Alavi Naeini; Writing -review \& editing: Iman Namjoo, Amirmansour Alavi Naeini, Mostafa Najafi, Mohammad Reza Aghaye Ghazvini, Akbar Hasanzadeh; Funding acquisition: Amirmansour Alavi Naeini; Resources: Iman Namjoo, Amirmansour Alavi Naeini, Mostafa Najafi, Mohammad Reza Aghaye Ghazvini, Akbar Hasanzadeh; Supervision: Amirmansour Alavi Naeini.

\section{Conflict of interest}

The authors declared no financial or personal conflicts of interest regarding the submission and publication of the manuscript.

\section{Acknowledgments}

The authors would like to thank the School of Nutrition \& Food Sciences, Isfahan University of Medical Sciences for their financial support. All participated children, their parents, physicians, and laboratory staff and officials are also appreciated.

\section{References:}

Anisman, H., Kokkinidis, L., \& Merali, Z. (1996). Interleukin-2 decreases accumbal dopamine efflux and responding for rewarding lateral hypothalamic stimulation. Brain Research, 731(1-2), 1-11. [DOI:10.1016/0006-8993(96)00460-X]

Anney, R. J. L., Lasky-Su, J., O’Dúshláine, C., Kenny, E., Neale, B. M., \& Mulligan, A., et al. (2008). Conduct disorder and ADHD: Evaluation of conduct problems as a categorical and quantitative trait in the international multicentre ADHD genetics study. American Journal of Medical Genetics. Part B: Neuropsychiatric Genetics, 147B(8), 1369-78. [DOI:10.1002/ ajmg.b.30871] [PMID]

Baecke, J. A., Burema, J., \& Frijters, J. E. (1982). A short questionnaire for the measurement of habitual physical activity in epidemiological studies. American Journal of Clinical Nutrition, 36(5), 936-42. [DOI:10.1093/ajcn/36.5.936] [PMID]

Balagopal, P., George, D., Patton, N., Yarandi, H., Roberts, W. L., \& Bayne, E., et al. (2005). Lifestyle-only intervention attenuates the inflammatory state associated with obesity: A rand- 
omized controlled study in adolescents. Journal of Pediatrics, 146(3), 342-8. [DOI:10.1016/j.jpeds.2004.11.033] [PMID]

Benton, D. (2010). The influence of dietary status on the cognitive performance of children. Molecular Nutrition $\mathcal{E}$ Food Research, 54(4), 457-70. [DOI:10.1002/mnfr.200900158] [PMID]

Bertran, N., Camps, J., Fernandez-Ballart, J., Arija, V., Ferre, N., \& Tous, M., et al. (2005). Diet and lifestyle are associated with serum C-reactive protein concentrations in a populationbased study. The Journal of Laboratory and Clinical Medicine, 145(1), 41-6. [DOI:10.1016/j.lab.2004.11.002] [PMID]

Bhatnagar, S., \& Taneja, S. (2001). Zinc and cognitive development. British Journal of Nutrition, 85(S2), S139-45. [DOI:10.1079/BJN2000306] [PMID]

Black, M. M. (1998). Zinc deficiency and child development. American Journal of Clinical Nutrition, 68(2 Suppl), 464S-9. [DOI:10.1093/ajcn/68.2.464S] [PMID] [PMCID]

Bryan, J., Osendarp, S., Hughes, D., Calvaresi, E., Baghurst, K., \& van Klinken, J. W. (2004). Nutrients for cognitive development in school-aged children. Nutrition Reviews, 62(8), 295-306. [DOI:10.1111/j.1753-4887.2004.tb00055.x] [PMID]

Carson, V., Ridgers, N. D., Howard, B. J., Winkler, E. A., Healy, G. N., \& Owen, N., et al. (2013). Light-intensity physical activity and cardiometabolic biomarkers in US adolescents. PLoS One, 8(8), e71417. [DOI:10.1371/journal.pone.0071417] [PMID] [PMCID]

Cha, H. R., Chang, S. Y., Chang, J. H., Kim, J. O., Yang, J. Y., \& Kim, C. H., et al. (2010). Downregulation of Th17 cells in the small intestine by disruption of gut flora in the absence of retinoic acid. Journal of Immunology, 184(12), 6799-806. [DOI:10.4049/jimmunol.0902944] [PMID]

Crosbie, J., \& Schachar, R. (2001). Deficient inhibition as a marker for familial ADHD. American Journal of Psychiatry, 158(11), 1884-90. [DOI:10.1176/appi.ajp.158.11.1884] [PMID]

DiGirolamo, A. M., \& Ramirez-Zea, M. (2009). Role of zinc in maternal and child mental health. American Journal of Clinical Nutrition, 89(3), 940S-5. [DOI:10.3945/ajcn.2008.26692C] [PMID] [PMCID]

Dittmann, S., Seemuller, F., Grunze, H. C., Schwarz, M. J., Zach, J., \& Fast, K., et al. (2008). The impact of homocysteine levels on cognition in euthymic bipolar patients: A cross-sectional study. The Journal of Clinical Psychiatry, 69(6), 899-906. [DOI:10.4088/JCP.v69n0603] [PMID]

Dunn, A. J., Wang, J., \& Ando, T. (1999). Effects of cytokines on cerebral neurotransmission. In R. Dantzer, E. E. Wollman, \& R. Yirmiya (Eds.), Cytokines, stress, and depression. Advances in experimental medicine and biology (pp. 117-127), Vol. 461 New York, NY: Springer. [DOI:10.1007/978-0-585-37970-8_8] [PMID]

Ertek, S., \& Cicero, A. (2012). Impact of physical activity on inflammation: Effects on cardiovascular disease risk and other inflammatory conditions. Archives of Medical Science, 8(5), 794-804. [DOI:10.5114/aoms.2012.31614] [PMID] [PMCID]

Eugene Arnold, L., Bozzolo, H., Hollway, J., Cook, A., DiSilvestro, R. A., \& Bozzolo, D. R., et al. (2005). Serum zinc correlates with parent- and teacher- rated inattention in children with attention-deficit/hyperactivity disorder. Journal of Child and Adolescent Psychopharmacology, 15(4), 628-36. [DOI:10.1089/ cap.2005.15.628] [PMID]
Fredrikson, G. N., Hedblad, B., Nilsson, J. A., Alm, R., Berglund G., \& Nilsson, J. (2004). Association between diet, lifestyle, metabolic cardiovascular risk factors, and plasma C-reactive protein levels. Metabolism-Clinical and Experimental, 53(11), 1436-42. [DOI:10.1016/j.metabol.2004.06.010] [PMID]

Ghayour-Mobarhan, M., Yaghootkar, H., Lanham-New, S. A., Lamb, D. J., \& Ferns, G. A. (2007). Association between serum CRP concentrations with dietary intake in healthy and dyslipidaemic patients. Asia Pacific Journal of Clinical Nutrition, 16(2), 262-8. [PMID]

Guney, E., Cetin, F. H., Alisik, M., Tunca, H., Tas Torun, Y., Iseri, E., et al. (2015). Attention deficit hyperactivity disorder and oxidative stress: A short term follow up study. Psychiatry Research, 229(1-2), 310-7. [DOI:10.1016/j.psychres.2015.07.003] [PMID]

Hamer, M., Sabia, S., Batty, G. D., Shipley, M. J., Tabak, A. G., Singh-Manoux, A., et al. (2012). Physical activity and inflammatory markers over 10 years: follow-up in men and women from the Whitehall II cohort study. Circulation, 126(8), 928-33. [DOI:10.1161/CIRCULATIONAHA.112.103879] [PMID] [PMCID]

Isasi, C. R., Deckelbaum, R. J., Tracy, R. P., Starc, T. J., Berglund, L., \& Shea, S. (2003). Physical fitness and C-reactive protein level in children and young adults: The Columbia University BioMarkers study. Pediatrics, 111(2), 332-8. [DOI:10.1542/ peds.111.2.332] [PMID]

Jiang, N. M., Tofail, F., Ma, J. Z., Haque, R., Kirkpatrick, B., \& Nelson, C. A., et al. (2017). Early life inflammation and neurodevelopmental outcome in Bangladeshi infants growing up in adversity. The American Journal of Tropical Medicine and Hygiene, 97(3), 974-9. [DOI:10.4269/ajtmh.17-0083] [PMID] [PMCID]

Joseph, N., Zhang-James, Y., Perl, A., \& Faraone, S. V. (2015). Oxidative stress and ADHD: A meta-analysis. Journal of Attention Disorders, 19(11), 915-24. [DOI:10.1177/1087054713510354] [PMID] [PMCID]

Karababa, I. F., Savas, S. N., Selek, S., Cicek, E., Cicek, E. I., \& Asoglu, M., et al. (2017). Homocysteine levels and oxidative stress parameters in patients with adult ADHD. Journal of Attention Disorders, 21(6), 487-93. [DOI:10.1177/1087054714538657] [PMID]

Kul, M., Unal, F., Kandemir, H., Sarkarati, B., Kilinc, K., \& Kandemir, S. B. (2015). Evaluation of oxidative metabolism in child and adolescent patients with attention deficit hyperactivity disorder. Psychiatry Investigation, 12(3), 361-6. [DOI:10.4306/pi.2015.12.3.361] [PMID] [PMCID]

Laimer, M., Ebenbichler, C. F., Kaser, S., Sandhofer, A., Weiss, H., \& Nehoda, H., et al. (2002). Markers of chronic inflammation and obesity: A prospective study on the reversibility of this association in middle-aged women undergoing weight loss by surgical intervention. International Journal of Obesity and Related Metabolic Disorders, 26(5), 659-62. [DOI:10.1038/ sj.ijo.0801970] [PMID]

Leviton, A., Allred, E. N., Fichorova, R. N., Kuban, K. C. K., Michael O'Shea, T., \& Dammann, O., et al. (2016). Systemic inflammation on postnatal days 21 and 28 and indicators of brain dysfunction 2 years later among children born before the 28th week of gestation. Early Human Development, 93, 25-32. [DOI:10.1016/j.earlhumdev.2015.11.004] [PMID] [PMCID] 
Ma, L., Chen, Y. H., Chen, H., Liu, Y. Y., \& Wang, Y. X. (2011) The function of hypothalamus-pituitary-adrenal axis in children with ADHD. Brain Research, 1368, 159-62. [DOI:10.1016/j. brainres.2010.10.045] [PMID]

Maddah, M., Eshraghian, M. R., Djazayery, A., \& Mirdamadi, R. (2003). Association of body mass index with educational level in Iranian men and women. European Journal of Clinical Nutrition, 57(7), 819-23. [DOI:10.1038/sj.ejcn.1601615] [PMID]

Martino, M., Rocchi, G., Escelsior, A., \& Fornaro, M. (2012). Immunomodulation mechanism of antidepressants: interactions between serotonin/norepinephrine balance and Th1/Th2 balance. Current Neuropharmacology, 10(2), 97-123. [DOI:10.21 74/157015912800604542] [PMID] [PMCID]

McCully, K. S. (2009). Chemical pathology of homocysteine. IV. Excitotoxicity, oxidative stress, endothelial dysfunction, and inflammation. Annals of Clinical and Laboratory Science, 39(3), 219-32. [PMID]

Miller, G. E., Freedland, K. E., Carney, R. M., Stetler, C. A., \& Banks, W. A. (2003). Pathways linking depression, adiposity, and inflammatory markers in healthy young adults. Brain, Behavior, and Immunity, 17(4), 276-85. [DOI:10.1016/S08891591(03)00057-6]

Mirmiran, P., Hosseini Esfahani, F., Mehrabi, Y., Hedayati, M., \& Azizi, F. (2010). Reliability and relative validity of an FFQ for nutrients in the Tehran lipid and glucose study. Public Health Nutrition, 13(5), 654-62. [DOI:10.1017/S1368980009991698] [PMID]

Mitchell, R. H., \& Goldstein, B. I. (2014). Inflammation in children and adolescents with neuropsychiatric disorders: A systematic review. Journal of the American Academy of Child and Adolescent Psychiatry, 53(3), 274-96. [DOI:10.1016/j. jaac.2013.11.013] [PMID]

Naghashpour, M., Amani, R., Nutr, R., Nematpour, S., \& Haghighizadeh, M. H. (2011). Riboflavin status and its association with serum hs-CRP levels among clinical nurses with depression. Journal of the American College of Nutrition, 30(5), 340-7. [DOI:10.1080/07315724.2011.10719977] [PMID]

Oades, R. D., Dauvermann, M. R., Schimmelmann, B. G. Schwarz, M. J., \& Myint, A. M. (2010). Attention-Deficit Hyperactivity Disorder (ADHD) and glial integrity: S100B, cytokines and kynurenine metabolism - effects of medication. Behavioral and Brain Functions, 6, 29. [DOI:10.1186/1744-90816-29] [PMID] [PMCID]

Oades, R. D., Myint, A. M., Dauvermann, M. R., Schimmelmann, B. G., \& Schwarz, M. J. (2010). Attention-Deficit Hyperactivity Disorder (ADHD) and glial integrity: An exploration of associations of cytokines and kynurenine metabolites with symptoms and attention. Behavioral and Brain Functions, 6, 32. [DOI:10.1186/1744-9081-6-32] [PMID] [PMCID]

Oztop, D., Altun, H., Baskol, G., \& Ozsoy, S. (2012). Oxidative stress in children with attention deficit hyperactivity disorder. Clinical Biochemistry, 45(10), 745-8. [DOI:10.1016/j.clinbiochem.2012.03.027] [PMID]

Papas, A. M. (1996). Determinants of antioxidant status in humans. Lipids, 31(1 Pt 1), S77. [DOI:10.1007/BF02637055] [PMID]

Pearson, T. A., Mensah, G. A., Wayne Alexander, R., Anderson, J. L., Cannon, R. O., \& Criqui, M., et al. (2003). Markers of inflammation and cardiovascular disease: Application to clinical and public health practice: A statement for healthcare professionals from the Centers for Disease Control and Prevention and the American Heart Association. Circulation, 107(3), 499-511. [DOI:10.1161/01.CIR.0000052939.59093.45] [PMID]

Penninx, B. W., Kritchevsky, S. B., Yaffe, K., Newman, A. B., Simonsick, E. M., \& Rubin, S., et al. (2003). Inflammatory markers and depressed mood in older persons: Results from the health, aging and body composition study. Biological Psychiatry, 54(5), 566-72. [DOI:10.1016/S0006-3223(02)01811-5]

Refsum, H., David Smith, A., Ueland, P. M., Nexo, E., Clarke, R., \& McPartlin, J., et al. (2004). Facts and recommendations about total homocysteine determinations: An expert opinion. Clinical Chemistry, 50(1), 3-32. [DOI:10.1373/clinchem.2003.021634] [PMID]

Ridker, P. M., Hennekens, C. H., Buring, J. E., \& Rifai, N. (2000). C-reactive protein and other markers of inflammation in the prediction of cardiovascular disease in women. The New England Journal of Medicine, 342(12), 836-43. [DOI:10.1056/ NEJM200003233421202] [PMID]

Seddon, J. M., Gensler, G., Klein, M. L., \& Milton, R. C. (2006). Creactive protein and homocysteine are associated with dietary and behavioral risk factors for age-related macular degeneration. Nutrition, 22(4), 441-3. [DOI:10.1016/j.nut.2005.12.004] [PMID]

Selek, S., Bulut, M., Ocak, A. R., Kalenderoglu, A., \& Savas, H. A. (2012). Evaluation of total oxidative status in adult attention deficit hyperactivity disorder and its diagnostic implications. Journal of Psychiatric Research, 46(4), 451-5. [DOI:10.1016/j. jpsychires.2011.12.007] [PMID]

Selek, S., Savas, H. A., Gergerlioglu, H. S., Bulut, M., \& Yilmaz, H. R. (2008). Oxidative imbalance in adult attention deficit/ hyperactivity disorder. Biological Psychology, 79(2), 256-9. [DOI:10.1016/j.biopsycho.2008.06.005] [PMID]

Sezen, H., Kandemir, H., Savik, E., Basmaci Kandemir, S., Kilicaslan, F., \& Bilinc, H., et al. (2016). Increased oxidative stress in children with attention deficit hyperactivity disorder. Redox Report, 21(6), 248-53. [DOI:10.1080/13510002.2015.1116729] [PMID] [PMCID]

Song, M., Lauseng, D., Lee, S., Nordstrom, M., \& Katch, V. (2016). Enhanced physical activity improves selected outcomes inchildren With ADHD: Systematic review. Western Journal of Nursing Research, 38(9), 1155-84. [DOI:10.1177/0193945916649954] [PMID]

Stadtman, E. R. (2006). Protein oxidation and aging. Free Radical Research, 40(12), 1250-8. [DOI:10.1080/10715760600918142] [PMID]

Stanger, O., Fowler, B., Piertzik, K., Huemer, M., Haschke-Becher, E., \& Semmler, A., et al. (2009). Homocysteine, folate and vitamin B12 in neuropsychiatric diseases: Review and treatment recommendations. Expert Review of Neurotherapeutics, 9(9), 1393-412. [DOI:10.1586/ern.09.75] [PMID] 
This Page Intentionally Left Blank 